Laporan Penelitian

\title{
Faktor yang berpengaruh terhadap kejadian presbikusis di rumah sakit Dr Kariadi Semarang
}

\author{
Melinda, Muyassaroh, Zulfikar \\ Departemen Telinga Hidung Tenggorok-Kepala Leher \\ Fakultas Kedokteran Universitas Diponegoro / Rumah Sakit Dr Kariadi, Semarang
}

\begin{abstract}
ABSTRAK
Latar belakang: Faktor risiko usia, hipertensi, diabetes melitus, hiperkolesterol dan kebiasaan merokok diduga dapat berpengaruh terhadap kejadian presbikusis. Belum terdapat data mengenai faktor risiko presbikusis di RSUP Dr.Kariadi, Semarang. Tujuan: menganalisis bagaimana pengaruh faktor usia, hipertensi, diabetes melitus (DM), hiperkolesterol, dan kebiasaan merokok terhadap kejadian presbikusis di RSUP DR. Kariadi Semarang. Metode: Penelitian analitik pada 45 kasus dan 45 kontrol pada subyek usia lanjut di klinik Geritatri RSUP Dr. Kariadi, Semarang pada periode April-Juni 2011. Data dasar dan faktor risiko diambil dari rekam medik. Dilakukan pemeriksaan otoskopi dan audiotimpanometri. Presbikusis bila gambaran timpanogram tipe A dan audiogram kurang pendengaran sensorineural simetris bilateral. Analisis statistik dilakukan dengan Uji Chi square, OR dan regresi logistik. Hasil: Didapatkan 45 subyek presbikusis(+) dan 45 subyek presbikusis(-), usia terbanyak yang menderita presbikusis $<75$ tahun sebanyak $29(32,2 \%)$. Usia berpengaruh terhadap kejadian presbikusis $(p=0,030, \mathrm{OR}=2,995$, $\mathrm{CI}=1,090-8,233)$, hipertensi berpengaruh terhadap kejadian presbikusis $(p=0,018, \mathrm{OR}=2,813, \mathrm{CI}=1,177$ 6,721). Diabetes melitus, hiperkolesterol, dan kebiasaan merokok tidak berpengaruh terhadap kejadian presbikusis. Kesimpulan: Usia, hipertensi secara sendiri sendiri atau bersama-sama berpengaruh terhadap kejadian presbikusis. Diabetes mellitus, hiperkolesterol, dan kebiasaan merokok tidak berpengaruh terhadap kejadian presbikusis.
\end{abstract}

Kata kunci : Presbikusis, faktor risiko, usia lanjut, hipertensi.

\section{ABSTRACT}

Background: Age, hypertension, diabetes mellitus, hypercholesterolemia, and smoking could be expected to affect the incidence of presbycusis. There is no data on risk factors of presbycusis in Dr. Kariadi Hospital Semarang. Purpose: To analyze how age, hypertension, diabetes mellitus. hypercholesterolemia, and smoking affect the incidence of presbycusis in Dr. Kariadi Hospital Semarang. Methods: Analytic case-control study on 90 elderly subjects in Geriatry clinic, Kariadi Hospital Semarang from April to June 2011. Basic data and risk factors were taken from medical records. Otoscopy examination performed followed by audiometry and timpanometry tests. Presbycusis was determined if the timpanogram was type-A and the audiogram symmetric bilateral SNHL. Statistical analysis by Chi square test, OR and logistic regression. Results: Obtained 45 subjects presbycusis (+) and 45 subjects presbycusis (-), most presbycusis subjects were in the age $<75$ years, which were 29 (32.2\%). Age found affected the incidence of presbycusis ( $p=0.030, O R=2.995, C I=1.090$ to 8.233), hypertension found affected the incidence of presbycusis ( $p=0.018, O R=2.813, C I=1.177$ to 6.721). Diabetes mellitus, hypercholesterolemia, and smoking habits found had no effect on the incidence of presbycusis. Conclusion: Age and hypertension alone or combined were found to affect the incidence of presbycusis. Diabetes mellitus, hypercholesterolemia, and smoking were not affecting the incidence of presbycusis.

Key words: Presbycusis, risk factors, elderly patients, hypertension.

Alamat korespondensi: Dr. Melinda, SpTHT-KL. email: melinda.ent72@gmail.com 


\section{PENDAHULUAN}

Presbikusis adalah kurang pendengaran sensorineural pada usia lanjut akibat proses degenerasi organ pendengaran, terjadi secara berangsur-angsur dan simetris. Terbanyak pada usia 70 - 80 tahun. Presbikusis dialami sekitar $30-35 \%$ pada populasi berusia $65-75$ tahun dan $40-50 \%$ pada populasi di atas 75 tahun. Prevalensi pada laki-laki sedikit lebih tinggi daripada wanita. ${ }^{1,2}$

Presbikusis merupakan salah satu masalah kesehatan yang terpenting dalam masyarakat. Hampir $40 \%$ penderita usia 65 tahun ke atas mengalami kurang pendengaran. Akibat kurang pendengaran tersebut penderita mengalami gangguan masalah sosial, seperti frustrasi, depresi, cemas, paranoid, merasa kesepian, dan meningkatnya angka kecelakaan. ${ }^{3}$

Komite nasional penanggulangan gangguan pendengaran dan ketulian menyatakan bahwa diperlukan pengetahuan, pengenalan, untuk dapat mendiagnosis presbikusis. Skrining pendengaran sebaiknya dilakukan pada penderita dengan usia diatas 60 tahun untuk menurunkan morbiditas akibat presbikusis. ${ }^{4}$ National Institute on Aging memberikan informasi sepertiga penduduk Amerika antara usia 65 - 74 tahun dan separuh penduduk berusia 85 tahun keatas memiliki kurang pendengaran jenis ini. ${ }^{5}$ Prevalensi tersebut meningkat pada tahun 2030 menjadi 70 juta orang. Di Indonesia jumlah penduduk usia lebih dari 60 tahun pada tahun 2005 diperkirakan mencapai 19,9 juta atau 8,48\% dan tahun 2025 diperkirakan penderita presbikusis akan meningkat menjadi 4 kali lipat dan dapat merupakan jumlah tertinggi di dunia. ${ }^{3}$ Data mengenai presbikusis belum pernah dilaporkan Di RSUP Dr. Kariadi Semarang.

Etiologi presbikusis belum diketahui secara pasti. Banyak faktor yang diduga dapat mempengaruhi terjadinya presbikusis. Berbagai penelitian telah dilakukan untuk mengetahui hubungan antara berbagai faktor risiko seperti usia, jenis kelamin, hipertensi, diabetes melitus (DM), hiperkolesterol dan kebiasaan merokok terhadap penurunan pendengaran pada usia lanjut. ${ }^{6}$ Penyakit seperti hipertensi, diabetes melitus (DM) dan hiperkolesterol secara langsung dapat mempengaruhi aliran pembuluh darah koklea dan menurunkan transportasi nutrisi akibat perubahan pembuluh darah, yang berakibat degenerasi sekunder pada saraf pendengaran. ${ }^{6}$

Lee $^{7}$ melaporkan bahwa terdapat hubungan antara usia dan jenis kelamin terhadap penurunan ambang dengar pada usia lanjut. Rata-rata nilai ambang dengar meningkat $1 \mathrm{~dB}$ setiap tahunnya pada usia 60 tahun ke atas dan terdapat perbedaan penurunan ambang dengar pada frekuensi 4 dan $8 \mathrm{kHz}$ secara signifikan antara laki-laki dan perempuan. Merokok dan riwayat bising pada usia lanjut berpengaruh terhadap penurunan nilai ambang dengar pada frekuensi 500, 2000 dan $4000 \mathrm{~Hz}^{8,9}$

Tujuan penelitian ini adalah untuk menganalisis pengaruh usia, hipertensi, diabetes DM, hiperkolesterol, dan kebiasaan merokok terhadap kejadian presbikusis di RSUP Dr. Kariadi Semarang.

\section{METODE}

Desain penelitian kasus kontrol pada semua penderita usia $\geq 55$ tahun yang datang berobat ke klinik Geriatri RSUP Dr.Kariadi Semarang periode April - Juni 2011. Jumlah sampel yang dibutuhkan adalah 29 tiap kelompok. Data dasar dan faktor risiko diambil dari rekam medik. Kriteria inklusi adalah hasil Pemeriksaan fisik THT dalam batas normal dan hasil timpanogram tipe A. Kriteria eksklusi yaitu adanya riwayat kurang pendengaran sejak kecil, terpapar suara bising selama 5-10 tahun, trauma kapitis dan gangguan keseimbangan. Semua sampel dilakukan pemeriksaan audiometri nada murni. Kasus atau presbikusis $(+)$ bila gambaran timpanogram normal/tipe A dan hasil audiogram kurang pendengaran sensorineural bilateral. Kontrol atau presbikusis(-) bila gambaran audiometri dan timpanometri dalam batas normal. Analisis data dengan uji chi-square dan odds 
Tabel 1. Pengaruh faktor risiko terhadap kejadian presbikusis

\begin{tabular}{lccccccc}
\hline \multicolumn{1}{c}{ Faktor risiko } & Kasus & $\mathbf{\%}$ & Kontrol & $\mathbf{\%}$ & OR & CI & $\boldsymbol{p}$ \\
\hline Usia $\geq 75$ & 16 & 17,9 & 7 & 7,8 & 2,995 & $1,090-$ & 0,030 \\
$\quad<75$ & 29 & 32,2 & 36 & 42,2 & & 8,233 & \\
Hipertensi (+) & 32 & 35,6 & 21 & 23,3 & 2,813 & $1,177-$ & 0,018 \\
Hipertensi (-) & 13 & 14,4 & 24 & 26,7 & & 6,721 & \\
DM (+) & 19 & 21,1 & 20 & 22,2 & 0,913 & $0,397-$ & 0,832 \\
DM (-) & 26 & 28,9 & 25 & 27,8 & & 2,103 & \\
Hiperkolesterol (+) & 22 & 24,4 & 18 & 20 & 1,435 & $0,622-$ & 0,396 \\
Hiperkolesterol (-) & 23 & 25,6 & 27 & 30 & & 3,307 & \\
Merokok (+) & 19 & 21,1 & 14 & 15,6 & 1,618 & $0,681-$ & 0,274 \\
Merokok (-) & 26 & 28,9 & 31 & 34,4 & & 3,843 & \\
\hline
\end{tabular}

ratio (OR). Analisis multivariat dengan regresi logistik untuk mencari faktor risiko yang paling berpengaruh terhadap kejadian presbikusis. Etical clearance disetujui Komite Etik Penelitian Fakultas Kedokteran Universitas Diponegoro/ RSUP Dr.Kariadi Semarang

\section{HASIL}

Didapatkan 45 sampel dengan presbikusis $(+)$ sebagai kelompok kasus, sedangkan kelompok kontrol adalah 45 sampel dengan presbikusis (-). Rerata usia kelompok kasus 72,27 tahun $( \pm 7,20$ tahun). Rerata usia pada kelompok kontrol 67,56 tahun $( \pm 6,57$ tahun). Kelompok usia terbanyak pada penelitian ini yang menderita presbikusis $<75$ tahun sebanyak 29 (32,2\%).

Kesan: Usia $\geq 75$ tahun memiliki risiko terjadi presbikusis 2,9 kali lebih besar dibanding usia $<75$ tahun. Hipertensi memiliki risiko terjadi presbikusis 2,8 kali lebih besar disbanding tidak hipertensi.

Tabel 2. Hasil analisis regresi logistik

\begin{tabular}{lccc}
\hline Faktor risiko & OR & CI & $\boldsymbol{p}$ \\
\hline Usia & 3,442 & $1,145-10,231$ & 0,028 \\
Hipertensi & 2,630 & $1,027-6,734$ & 0,044 \\
DM & 1,171 & $0,472-2,904$ & 0,733 \\
Hiperkolesterol & 1,404 & $0,553-3,568$ & 0,475 \\
Merokok & 1,332 & $0,527-3,365$ & 0,545 \\
\hline
\end{tabular}

\section{DISKUSI}

Presbikusis adalah kurang pendengaran sensorineral pada usia lanjut akibat proses degenerasi. Faktor risiko hipertensi, DM, merokok, lingkungan bising, gaya hidup dan genetik dapat mempengaruhi kejadian presbikusis. ${ }^{6,10}$

Pada hasil penelitian didapatkan kejadian presbikusis hampir 30-45\% timbul pada dekade 6-7. Penelitian ini sesuai dengan penelitian di South Carolina USA, didapatkan usia presbikusis terbanyak pada dekade 6-7 tahun. ${ }^{10}$ Berbeda dengan penelitian di Qatar yang menemukan prevalensi usia presbikusis terbanyak pada kelompok middle age yaitu 50-59 tahun. Hal ini dapat disebabkan karena pada penelitian tersebut menggunakan subyek dengan DM, sehingga kemungkinan terjadinya presbikusis muncul lebih awal. Penelitian di Qatar dilaporkan lakilaki 52,6\% lebih banyak dibanding perempuan 49,5\%. ${ }^{11}$ Penelitian di South Carolina USA, ditemukan frekuensi laki-laki 52,1\% lebih banyak dari perempuan $48,4 \% .{ }^{10}$ Hasil ini sesuai dengan penelitian yang telah dilakukan, laki-laki mempunyai frekuensi lebih banyak daripada perempuan. Penelitian gen oleh Translational Genomics Research Institute (TGen) di Santa Clara, California, dan University of Antwerp, Belgia tidak menjelaskan mengapa laki-laki lebih rentan untuk mengalami presbikusis, namun mereka menemukan satu gen paling menonjol 
(GRM7) yang menghasilkan glutamat dan dapat menyebabkan kerusakan pada sel-sel rambut dalam dan luar telinga akibat bertambahnya usia sehingga menyebabkan gangguan pendengaran. ${ }^{12}$

Hasil penelitian mendapatkan usia berpengaruh terhadap kejadian presbikusis $p=0,030$. Usia $\geq 75$ tahun memiliki risiko terjadi presbikusis 2,9 kali lebih besar dibanding usia $<75$ tahun. Johnson $^{2}$ menuliskan bahwa pada usia 70 tahun, kurang pendengaran belum begitu terasa sedangkan pada usia lebih tua kurang pendengaran lebih nyata. Hasil penelitian Johnson menemukan adanya perbedaan yang signifikan pada penurunan nilai ambang dengar subyek berusia 75 tahun dibanding subyek berusia 70 tahun. Sesuai dengan teori bahwa dengan bertambahnya usia maka kemungkinan terjadinya degenerasi semakin tinggi termasuk pada organ pendengaran sehingga fungsinya akan menurun.

Hipertensi yang berlangsung lama dapat memperberat tahanan vaskuler yang mengakibatkan disfungsi sel endotel pembuluh darah. Patogenesis sistem sirkulatorik dapat terjadi pada pembuluh darah organ telinga dalam disertai peningkatan viskositas darah, penurunan aliran darah kapiler dan transpor oksigen. Akibatnya terjadi kerusakan sel-sel auditori, dan proses transmisi sinyal yang dapat menimbulkan gangguan komunikasi. ${ }^{13}$

Hasil penelitian ini didapatkan penderita hipertensi pada presbikusis $35,6 \%$, lebih banyak dibanding tidak presbikusis dengan perbandingan 1,5:1. Faktor risiko hipertensi pada penelitian ini berhubungan dengan kejadian presbikusis $p=0,018$. Hipertensi berisiko menimbulkan presbikusis 2,8 kali dibandingkan tanpa hipertensi. Sesuai penelitian Mondelli ${ }^{14}$ didapatkan penderita hipertensi $65 \%$ mempunyai hubungan dengan kejadian kurang pendengaran tipe sensorineural pada usia lanjut.

DM dapat menyebabkan mikroangiopati organ koklea, dapat terjadi atrofi dan berkurangnya sel rambut. Neuropati pada vasa nervosum nervus VIII, ligamentum dan ganglion spiral ditandai kerusakan sel Schwann, degenerasi myelin, dan kerusakan akson yang berakibat dapat menimbulkan penurunan pendengaran. ${ }^{15}$ Hubungan antara DM dan kejadian penurunan pendengaran masih dalam perdebatan walaupun secara teori terdapat hubungan antara hiperglikemia dengan terjadinya penurunan pendengaran. ${ }^{16}$ Analisis pengaruh DM terhadap kejadian presbikusis pada penelitian ini didapatkan bahwa DM tidak berhubungan dengan kejadian presbikusis $p=0,832$. Hasil ini bertentangan dengan peneliti sebelumnya yang mengatakan terdapat penurunan nilai ambang dengar secara signifikan pada penderita DM. Benner ${ }^{11}$ menyatakan terdapat hubungan yang bermakna antara penderita DM dengan kurang pendengaran pada usia lanjut, $p=0,034$. Perbedaan tersebut kemungkinan disebabkan karena subyek dengan DM yang menderita presbikusis lebih sedikit dibanding tidak menderita presbikusis. Kesadaran subyek untuk memeriksakan kesehatan secara rutin lebih baik sehingga hal ini dapat mencegah terjadinya presbikusis.

Hiperkolesterol dapat menyebabkan penebalan dan hilangnya elastisitas pembuluh nadi yang berakibat terjadi menyempitan lumen, disebut mikroangiopati. Akibat mikroangiopati organ koklea akan terjadi atrofi dan berkurangnya sel rambut sehingga dapat menimbulkan penurunan pendengaran. ${ }^{15}$ Hasil penelitian ini didapatkan hiperkolesterol tidak berhubungan dengan kejadian presbikusis. Hasil ini berbeda dengan penelitian Fernanda ${ }^{13}$ yang melaporkan bahwa $71 \%$ penderita hiperkolesterol usia lanjut mengalami penurunan pendengaran dibandingkan penderita tidak hiperkolesterol, dengan nilai $p<0,05$. Perbedaan tersebut kemungkinan karena jumlah presbikusis dengan hiperkolesterol tidak berbeda jauh dengan subyek yang tidak presbikusis menderita hiperkolesterol.

Rokok mengandung nikotin dan karbonmonoksida yang mempunyai efek iskemia, Akibat iskemia terjadi gangguan suplai oksigen ke organ korti sehingga terjadi gangguan pendengaran. Efek lain dapat terjadi spasme pembuluh darah, kekentalan darah, dan arteriosklerotik. ${ }^{17,18}$ 
Hasil analisis kebiasaan merokok terhadap presbikusis tidak menunjukkan adanya hubungan, $p$ $=0,274$. Berbeda dengan penelitian Cruickshanks ${ }^{9}$ menyatakan bahwa terdapat hubungan antara kebiasaan merokok dan penurunan pendengaran pada usia lanjut. Kebiasaan merokok mempunyai risiko sebesar 1,69 kali dibanding tidak merokok. Laki-laki perokok tanpa riwayat terpapar bising mengalami penurunan pendengaran pada frekuensi $4000 \mathrm{~Hz}$ dibandingkan bukan perokok. Perbedaan ini kemungkinan disebabkan karena data kebiasaan merokok diambil dari anamnesis sehingga bersifat subyektif.

Hasil analisis regresi logistik didapatkan usia dan hipertensi baik secara sendiri-sendiri atau bersama-sama berpengaruh terhadap kejadian presbikusis. Hal ini sesuai pernyataan bahwa sejalan dengan bertambahnya usia, hampir setiap orang mengalami kenaikan tekanan darah. Tekanan sistolik terus meningkat sampai usia 80 tahun dan tekanan diastolik terus meningkat sampai usia 55-60. ${ }^{19}$ Bertambahnya usia disertai hipertensi, akan memicu terjadinya proses degenerasi dan penurunan fungsi organ pendengaran. ${ }^{1,2}$

Dari penelitian ini dapat disimpulkan bahwa usia dan hipertensi merupakan faktor risiko yang berpengaruh terhadap kejadian presbikusis, sehingga diperlukan kontrol hipertensi untuk mencegah progresifitas presbikusis. Diabetes melitus, hiperkolesterol, dan kebiasaan merokok tidak berpengaruh terhadap kejadian presbikusis di RSUP Dr. Kariadi Semarang. Kekurangan pada penelitian ini ialah tidak dilakukannya pemeriksaan genetik yang mungkin berpengaruh terhadap kejadian presbikusis. Selain itu, data faktor risiko diabetes melitus serta hiperkolesterol, tidak dipisah-pisahkan berdasarkan lama sakit dan terkontrol atau tidak terkontrol.

\section{DAFTAR PUSTAKA}

1. Bluestones CD, ed. Definitions. London: BC Decker Inc; 1999. p.85-103.

2. Jönsson R, Rosenhall U, Gause-Nilsson I, Steen B. Auditory function in 70- and 75-year-olds of four age cohorts. Scan Audiol 1998; 27:81-93.
3. Sirlan F, Suwento R. Laporan hasil survey indera penglihatan dan pendengaran 1993-1996. Ditjen Pembinaan Kesehatan Masyarakat; Jakarta, 1998.

4. Gates GA, Murphy M, Rees TS, Fraher A. Screening for handicapping hearing loss in the elderly. J Fam Pract 2003; 52:56-62.

5. National Institute on aging, hearing and older people. [online] 1999 December [cited 2010 April]; Available from:URL: http://www.nih.gov./na/health/pub/hearing. htm.

6. Suwento R, Hendarmin H. Gangguan pendengaran pada geriatri. Dalam: Soepardi EA, Iskandar N, Bashiruddin J, Restuti RD, eds. Buku ajar ilmu kesehatan telinga hidung tenggorok kepala dan leher. Edisi ke-6. Jakarta: Balai penerbit FKUI; 2007. hal.10-43.

7. Lee FS, Matthew LJ, Dubno JR, Mills JH. Longitudinal study of pure-tone thresholds in older persons. Ear Hear 2005; 26(1):1-11.

8. Cruickshanks KJ, Theodore TL, Klein B, Klein R, Perlman JA, Nondahl DM. Prevalence of hearing loss in older adults in Beaverdam, Wisconsin. The epidemiology of hearing loss study. Am J of Epidemiol 1998; 148:9.

9. Cruickshanks KJ, Klein R, Klein B, Wiley TL, Nondahl DM, Tweed TS. Cigarette smoking and hearing loss: The epidemiology of hearing loss study. JAMA 1998; 279(21):1715-19.

10. Gates GA, Mills JH. Presbycusis. Lancet 2005; 366:1111-20

11. Bener A, Salahudin A, Darwish S, Al-Hamaq A, Gansan L. Association between hearing loss and type 2 diabetes mellitus in elderly people in a newly developed society. Biomed Res 2008; 19(3):187-95

12. Friederman R. Human genetic molecular. [online] 2008 December [cited 2011 Agustus]; Available from : URL : www. http://hmg.oxfordjournals.org/

13. Tobian L. Hyperrtension. Am J 1991; 17:1-52

14. Mondelli MF, Lopes AC. Relation between arterial hypertension and hearing loss. Intl Arch Otorhinolaryngol 2009; 13:63-68.

15. Frisina ST, Mapes F, Kim SH. Characterization of hearing loss in aged type II diabetic. Hear Res 2006; 211:103-13.

16. Kakarlapudi V, Sawyer R, Staecker H. The effect of diabetes on sensorineural heaaring loss. Otol Neurotol 2003; 24:382-6

17. Pengaruh Rokok Terhadap Pendengaran. [online] 2010 January [cited 2010 October]; Available from: URL: http://www. http://forum.upi.edu/v3/index.php

18. Laviolette SR, Kooy VD. The neurobiology of nicotine addiction: bridging the gap from molecules to behavior. Nature Rev Neurosci 2004; 5:55-65.

19. The sixth report of the joint national committee on prevention, detection, evaluation, and treatment of high blood pressure. NIH Publication no. 98: 4080. Rochester, MN: Mayo clinic, Mayo foundation, Mayo medical school, Nov.1997. 